\title{
NEW EVERBEARING STRAWBERRIES
}

\author{
W. VAN FleEt \\ Bureau of Plant Industry, United States Department of Agriculture
}

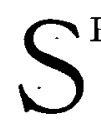

EVERAL varieties of stra wberries that continue under favorable conditions to fruit throughout the summer and autumn after bearing a fair spring crop of berries have lately come into favor. All are descendants of the Pan American, a sport or mutation of the Bismack, a former commercial variety of the Fragaria virginiana type in which the runners are to a great extent suppressed, favoring the successional production of fruiting crowns during the growing season. This peculiarity appears heritable in many seedlings and hybrids of Pan American, and the horticultural section thus established has been given the convenient but somewhat misleading name of "everbearing," as special cultural requirements in the way of moisture and fertilization are needed to insure fruit formation and plant increase during the most exacting summer months. Progressive and Superb are the most popular varieties of the new type and are increasingly planted. They leave something to be desired in productiveness and plant-making capacity, as few runners are thrown out from the more prolific plants. Seedlings continue to be grown from the present everbearing varieties, and crossings have been made by several growers with spring-fruiting commercial varicties and varieties of the European Alpine strawberry Fragaria vesca, which naturally fruits over a long season, in the hope of developing features of additional value. Fragaria vesca in the European and Mexican Alpine forms has rarely proved worth cultivating in North America, as the plants do not well endure our hot sunlight and the berries, though well flavored, are small and soft in texture.

While traveling in Chile as an agri- cultural explorer in 1914, Prof. IV. F. Wight, of the Bureau of Plant Industry, forwarded seeds of a fairly largefruited Alpine strawberry occasionally sold in the -Santiago markets. The type is that of Fragaria vesca, but whether native or introduced could not be ascertained. When grown in the introduction gardens at Rockville, Md., and Chico, Cal., of the Office of 'Foreign Seed and Plant Introduction; certain of the resulting plants showed greater vigor, fruitfulness and general adaptation to our climatic conditions than any Alpine hitherto introduced. They have endured our hot, dry summers, fruiting continuously from June until frost under the most ordinary cultural treatment, at the same time throwing out an abundance of strong runners. The berries are well flavored, but lack firm texture and sufficient size to be of practical value. Plants have been disseminated in a limited way for further trial under the introduction number of 35005. The ability of this South American strawberry to fruit and produce runners simultaneously throughout the summer and autumn suggested the possibility of developing large-fruited varieties holding the same characteristics by hybridizing it with practical commercial spring-bearing sorts. Chesapeake and Early Jersey Giant were selected for the purpose as being well adapted to local conditions at Bell Experiment Plot, Glendale, Md. Pollinations were carefully made under glass in February, 1916, and the resulting seedlings grown in the field. About 400 fruited in June, 1917, showing high average merit as June-fruiting varieties, but with no obvious tendency toward continuous bearing.

Runners from two of the best plants were rooted in pots during summer, 


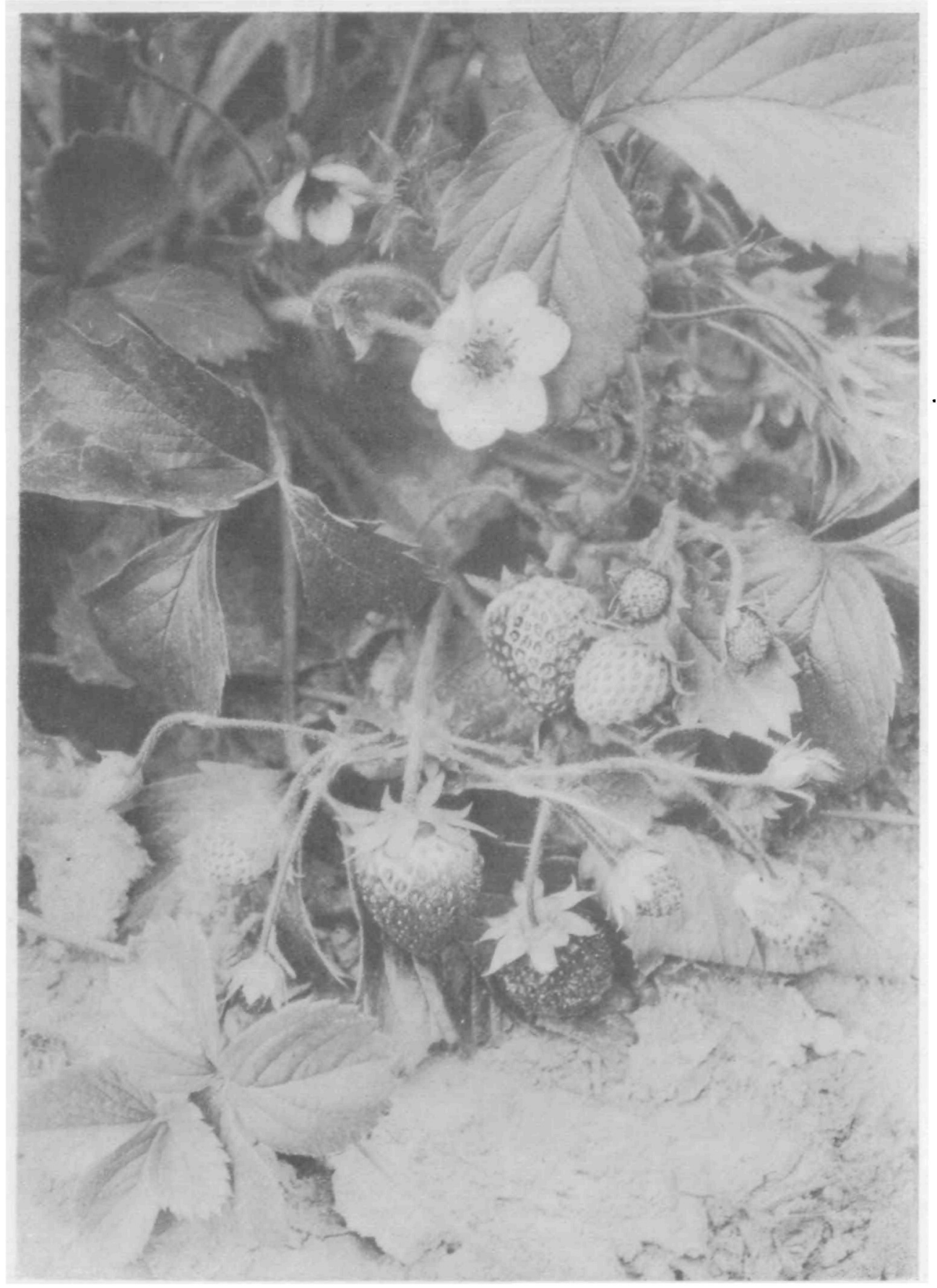

A NEW "EVERBEARING" STRAWBERRY

This variety of strawberry continue sunder favorable conditions to fruit throughout the summer and autumn after bearing a crop in the spring. It is the result of a cross between Fragaria chiloensis and F. vesca. Photographed by Crandall. (Fig. 7.) 


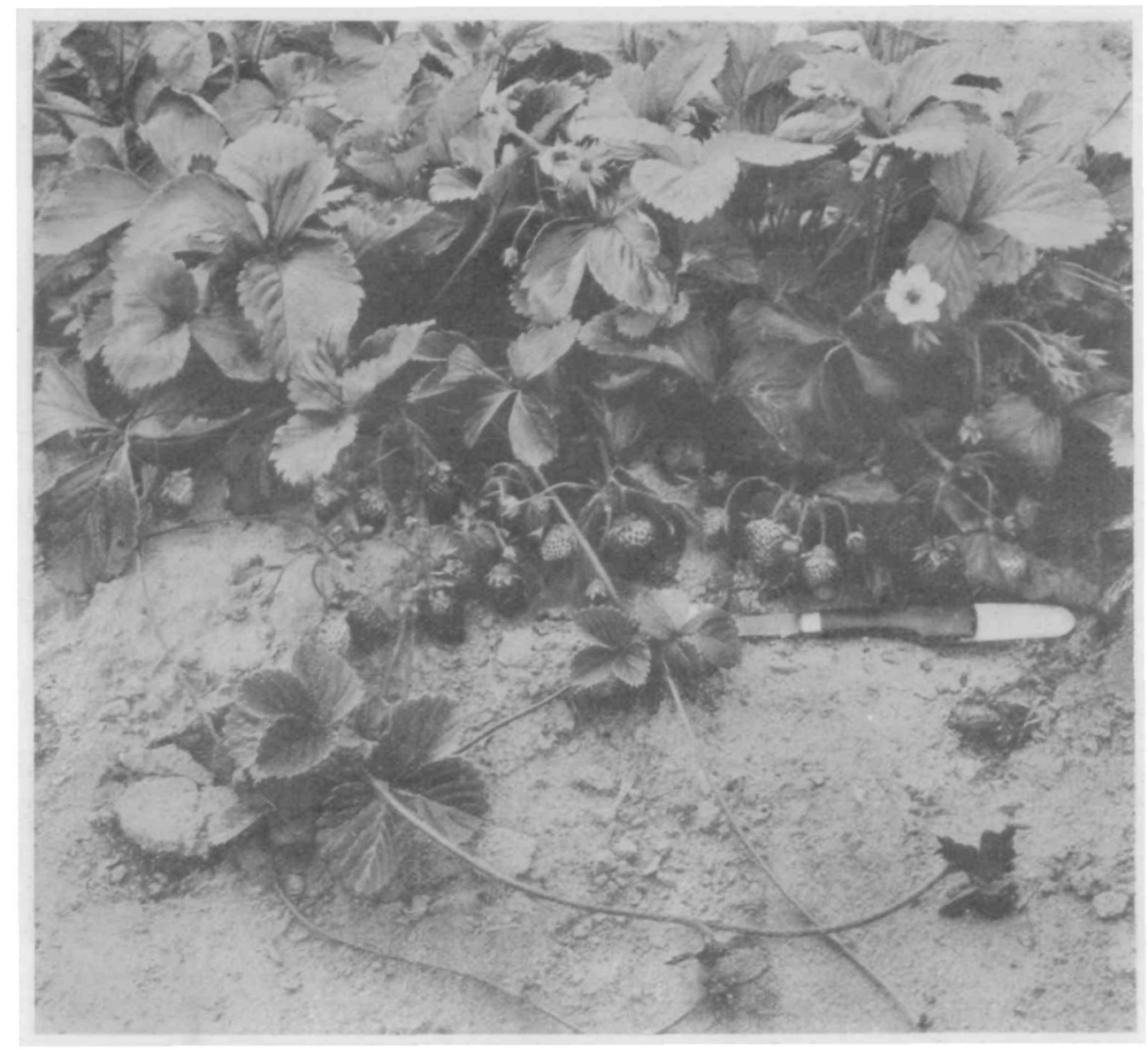

\section{A NEW "EVERBEARING" STRA WTERRY}

Another view of the new cross produced at Bell Experiment Plot, Glendale, Md. Photographed by Crandall. (Fig. 8.)

brought into bloom under glass early in 1917, and again pollinated with No. 33005 , something over 150 seedlings resulting, four of which bore handsome, large berries continuously from July until November the past season, producing a good supply of vigorous runners at the same time. The plants shown in the illustration were photographed September 26 and continued to ripen fruit for several weeks. In appearance, size and quality the berries most favorably conpare with the best of the everbearing varieties now in cultivation, while the plant-making propensities rival those of the commercial spring-fruiting kinds. If, as now appears probable, superior continuousbearing strawberries with free runner production can be developed by the use of an Alpine variety adapted to the American climate, there will be little need to depend on the progeny of the mutant Pan American, with its inherent tendency toward slow plant increase. 